a clear interval of a year or even of several months in which no evidence of recurrence is forthcoming it would seem that the return must be looked upon as a reinfection. In the same manner metastatic deposits are due to a transference of cells from the original growth which has not been removed early enough. But this explanation is insufficient to account for cases where secondary growths have taken place two, three, or more years after removal, especially when the patient has remained well and has increased in weight during the greater part of the interval. The recurrence in these cases must be attributed to reinfection and the cancer is a new growth in every sense of the term.

I should be especially pleased to receive information about cases of malignant disease where recurrence or metastatic growths have occurred either immediately or remotely. I mean by immediate cases those in which there are further signs of malignancy within a year of an operation performed by a competent surgeon in an early case and upon a part of the body where he might reasonably expect to remove the entire disease, as in a scirrhus of the breast with a moderate affection of the axillary glands. In such circumstances I want to ascertain whether the recurrences or secondary deposits are more frequent in people who go back to their former homes and to the daily duties of the lives to which they had been accustomed, or whether they are more common in those who from whatever cause have made a radical alteration in their mode of life or who have had occasion to change their place of abode? The questions are doubtless difficult to answer and it would be necessary to tabulate a large number of cases before any conclusion could be arrived at. But some of us may have the opportunity of occasionally comparing cases which have so many points in common as to be fairly comparable. If such a group of cases should present itself for examination it would be desirable to ascertain whether any special factor was present in the cases of early recurrence which was absent in those who remained free from further signs of cancer. In Cases 1 and 2 , which are recorded above, the points of distinction seem to be the radical alteration in the life and habits of the patient who racovered, whilst the patient who died pursued the even tenour of her way. In Cases 3 and 4 it appeared as if the sudden onset of domestic worry in a woman who had previously led a most uneventful life (Case 3) was the determining cause of the recurrence, whilst the other patient (Case 4) was relieved from the anxiety of earning her daily bread and attained a more healthy state of life.

Metastatic growths are due to the migration of cancer cells from a pre-existing centre of malignant disease. This migration of cells must be very great under ordinary conditions and must be taking place in every direction. But secondary growths are not universal in every case of cancer, nor are they always very widely distributed. The normal tissues therefore must have the power of destroying the cancer cells which become lodged in them. The destructive power is limited, no doubt, and varies in each individual, but it is quite legitimate to suppose that the sudden lowering of the general vitality might arrest it and so allow of a sufficient growth of cancer cells to produce an enlargement of the lymphatic glands or recurrence in a distant organ. The chief fallacy involved in any examination of cases of early recurrence lies in the fact that the original growth has not been completely removed, but this error should be negligible when the operation has been performed early by a surgeon who is accustomed to operate upon cases of malignant disease.

Cases of recurrence occurring long after the original operation and when a cure seems to have been obtained are most interesting and are well worthy of a more careful examination than they appear to have received up to the present time, the main points to be determined being, as in the former set of cases, the changes which have taken place in the habits and habitation of the individual. Such were Cases 6 and 7 of this series in which both patients had undergone a complete change of environment. Envirunment, too, seems to have exercised some influence upon the malignant growth from which the patient in Case 5 suffered. The tumour grew whilst he was in London, remained quiescent when he was abroad, and grew again rapidly when he returned home. In this case there may have been some individual factors as well as the mere surroundings to be taken into account, becanse the patient returned to a house where his wife had previously died from cancer and almost certainly resumed a mode of life which must have been completely interrupted whilst he was abroad.
A chemical theory of the origin of cancer would therefore explain the circumstances in this case as well as, or perhaps better than, any theory of reinfection.

Everyone knows that malignant growths do not run a uniform course even when they seem to be structurally identical, but no one, I think, has made any attempt to determine whether the irregularities are due to the malignant growth, to the individual in whom it grows, or to the surroundings of the individual. I am here engaged in considering the individual and his surroundings rather than the growth from which he is suffering, for it seems extremely desirable to ascertain whether the recurrences in malignant disease are really as capricious as they are generally supposed to be or whether there may not be some underlying reason to explain why they appear in some persons but not in others and at such varying times after the original operation. The cases which I have brought forward raise a suspicion in my own mind that recurrence in cancer is not so arbitrary as it appears at first sight to be, but that there may be some underlying causes, such as locality and alterations in the bodily condition of the patient, which may accelerate, retard, or even entirely prevent its appearance. The subject, however, must be approached with quite an open mind and there must be stronger grounds for the suspicion before it is acted upon. Cancer patients have quite enough to bear as it is and $I$ should be the last to add to their sufferings by recommending them to break up their homes as a routine proceeding after every operation for the removal of a malignant growth. Every now and then cases occur in which such a radical change of surroundings does take place and these are the cases which I should like the medical attendants carefully to watch.

Chandos-street, W.

\section{HEPATECTOMY FOR THE REMOVAL OF} RIEDEL'S LOBE.

BY CHARLES BARRETT LOCKWOOD, F.R.C.S. ENG., ASSISTANT SURGEON TO ST. BARTHOLOMEW's HOSPITAL; PRESIDENT OT THE ANATOMICAL SOCIETY OF GREAT BRITAIN AND IRELAND.

ALTHOUGH Riedel's lobe of the liver is not a commors abnormality, nevertheless it has to be taken into considera. tion in the diagnosis of abdominal tumours and circum. stances may justify its removal. Riedel's lobe of the liver is a tongue-shaped piece of healthy liver which hangs from the right lobe. The tongue is continuous with the right lobe of the liver immediately to the right of the fissure for the gall-bladder. When I excised Riedel's lobe the gall-bladder formed the left end of the incision into the liver and care had to be taken not to transfix it with the needle. Riedel's lobe may be united to the right lobe of the liver by a broad thick base such as is shown in Dr. Arthur Keith's drawings anc in all of the eight figures which Riedel gives in his original communication. The title of this is almost an epitome and is as follows: "Ueber den zungenförmigen Fortsatz des rechten Leberlappens und seine pathognostiche Bedeutung für die Erkrankung der Gallenblase nebst Bemerkungen über Gallenstein-Operationen." 2 The term "tongue-shaped process" gives the mind a very clear idea of the usual shape. But Riedel's lobe may be united to the right lobe of the liver by a base which has a broad shallow groove which is best seen in front. This was its condition in the case in which I performed hepatectomy. But sometimes Riedel's lobe has a distiret neck and hangs from the liver like a huge polypus. recollect seeing such a one in the dissecting-room when was demonstrator of anatomy, and in 18961 mistook ansther one of the same kind for a distended gall-bladder. The circumstances of this case were briefly as follows.

A middle-aged woman had suffered for many months from a pain a little below the eighth costal cartilage of the right side. Inasmuch as all the symptoms clearly pointed to the gall-bladder, a surgeon in the country performed laparotomy. The gall-bladder contained no stones but was

1 The Nature and Anatomy of Fnteroptosis (Glénard's Disease) The Laycet, March 14th, 1903, p. 709, Figs. 14 and 15 2 Berliner Klinische Wochenschrift, 1888, pp. 577 and 602 . 
full of bile which could be expelled by squeezing. The abdomen was closed without anything more being done to the gall-bladder. The pain having persisted I was asked by Dr. W. J. O'Meara to see the patient. The clinical symptoms pointed very clearly to an affection of the gall-bladder and, in addition, an oval tumour exactly like a distended gall-bladder could be felt beneath the right linea semilunaris. When the abdomen was opened a large and slightly distended gall-bladder was met with, but it was clearly not hard enough to be felt through the abdominal wall. At the right of the gall-bladder a Riedel's lobe extended beneath the right linea semilunaris into the abdomen for at least three inches beyond the costal margin and was attached to the liver by a thick neck. In Sir Lauder Brunton's case an elastic swelling was felt in the right iliac region of a woman. It was diagnosed as an enormously dilated gall-bladder, but when the patient had died from malignant disease a very long gall-bladder with a correspondingly elongated right lobe of the liver were discovered. ${ }^{3}$ Clearly the latter was the tumour which had been left before the operation. In my case the flaccid gallbladder was explored but no stone was discovered. It contained several ounces of thin bile-stained mucus. A drain was inserted and kept in for a fortnight. Dr. O'Meara informs me that the patient is cured of her pain and discomfort which had evidently been caused by catarrh of the gall-bladder.

This operation was performed in 1896 and although I perform many abdominal operations, nevertheless I did not again ensounter Riedel's lobe until nearly six years had elapsed and this was the one in which hepatectomy was performed. The patient was a young unmarried woman who complained of abdominal pain. This pain was said to be continuous and situated in the right side and to be worst at ivicBurney's point. A tumour could be felt just outside the middle third of the right linea semilunaris. The tumour moved with respiration; it was smooth and painless and slipped back towards the right lumbar region in just the same way as a displaced and moveable kidney does. Moreover, it seemed to be separated from the liver by an area of resonance. Therefore a displaced and moveable kidney was diagnosed and a belt and horsehoe pad were applied, but without any relief. The pain was so persistent at McBurney's point and accompanied by so much flatulence and constipation that the suspicion arose that the case might be one in which the displaced and moveable kidney had become complicated with appendicitis. After having had the young woman under observation for some days and after having examined her under an anæsthetic, this suspicion seemed to be strengthened and the appendix was removed on July 19th, 1902, through the usual oblique incision. Both macroscopically and microscopically it proved to be normal. But this operation also gave me an opportunity of ascertaining the nature of the tumour which could be felt just to the onter edge of the right rectus. Twice before I have had to remove displaced and moveable kidneys because they were hydronephrotic ; moreover, they sometimes contain calculi. However, I was rather surprised to find that the tumour hung down from the right lobe of the liver and was attached to it by a thick neck. The exploration and removal of the appendix caused but little disturbance and the patient went away wearing a belt and horseshoe pad. After a while she returned still complaining of the pain in her right side which, she said, made her life a burden to her and hindered her from earning her living.

In October, 1902, I showed the patient to my colleagues in consultation and they agreed with me that the removal of the tumour was justifiable in the circumstances. However, before operating a period of rest in bed was tried and resulted in some abatement of the pain, but she came back again complaining that the pain returned as soon as she tried to work. Therefore on Feb. 28th, 1903, an incision three inches long was made into the abdomen opposite the middle of the right linea semilunaris. The tumour was easily withdrawn until its junction with the right lobe of the liver came into view. The junction was marked by a broad shallow groove. Anterior and posterior incisions were carried obliquely into the base of the tumour from without inwards so as to remove it and to leave a pair of flaps of liver substance. Some of the hepatic vessels bled and were secured with an

3 The LaNCET, Feb. 1st, 1896, p. 293, and in the Transactions of the Medical Society of London, vol. xix., p. 116. encircling suture of No. 00 twisted silk. This suture was buried in the liver substance by transfixing the latter with a small, fully curved Hagedorn's needle. When the bleeding had been stopped in this manner the flaps of liver substance were brought together with about eight or ten sutures of No. 3 twisted silk. This thickness was chosen to try to prevent the sutures cutting out through the liver substance, but I found the healthy liver to be much tougher and much less vascular than in cases in which $I$ have had to explore it to find abscesses or hydatids. The operation was concluded in the usual way by closing the layers of the abdominal wall with rows of buried silk sutures. The patient made a rapid and perfect recovery and when last seen (four months after the operation) was well and free from pain. The gallbladder was carefully examined and was found to be perfectly healthy, a point of some importance, because Riedel assumes that the formation of the lobe is related to the enlargement of that reservoir. ${ }^{4}$

I have purposely called the lobe of the liver which was excised by Riedel's name. The name "linguiform ${ }^{5}$ process" which he originally gave to it does not, to my mind, indicate all the shapes which it may assume. If the process always became wider at its junction with the liver and always wanted a groove it would be more like a tongue and could not easily be confounded with a displaced and moveable kidney. Moreover, the term "Riedel's lobe" has other advantages, for it does not suggest any theory of causation or any clinical peculiarity. In my case there was nothing to suggest "a partial or local ptosis of the liver" (Treves) or that it was due to tight-lacing (Quincke and Hoppe-Seyler). We are indebted to Sir Frederick Treves ${ }^{6}$ for one of the best accounts of Riedel's lobe. In this the "wholesale excision" of the adventitious lobe is pronounced to be unjustifiable. Everyone would agree with this opinion when, as in my first case, there is disease of the gall-bladder, especially if it be true that cholecystotomy is followed by disappearance of the lobe. But in the instance under consideration the gall-bladder was perfectly healthy. The patient was fully conscious of the presence of the tumour and, whether rightly or wrongly, attributed the persistence of her sufferings to its presence. Doubtless our opinions upon the question of the propriety of the operation of excision must be greatly biased by our estimate of its dangers. A fair experience of operations upon the liver has led me to believe that it is an organ which is singularly tolerant of surgical interference and that hæmorrhage from its substance is easily controlled and not to be dreaded. ${ }^{7}$ Such were the reasons which prompted me to excise the tumour rather than to resort, as Billroth and others have done, to an attempt at suturing.

Upper Berkeley-street, W.

\section{ENZYMES IN TUMOURS.}

\section{BY ARTHUR HARDEN}

\section{$A N D$}

ALLAN MACFADYEN.

(From the Jenner Institute of Preventive Medicine.)

THE study of the nature of malignant processes has been mainly devoted to the investigation of the morbid anatomy of the affected tissues and of the cancer cell in particular, whilst research as regards the origin of such processes has been largely based on a parasitic theory of their origin. There is, however, another factor of which our knowledge is at present scanty and imperfect-viz., the functional modifications that take place in the cellular elements of the tissues when diseased. A more intimate knowledge of the metabolism and more particularly of the intracellular metabolism of the tissues would throw light upon many points that remain obscure and perplexing to the clinician and pathologist. The bio-chemical study of any disease process constitutes a distinct and essential branch of inquiry.

4 Erfahrungen ïber die Gallensteinkrankheit, Berlin, 1892, p. 57.

Synonyms : appendicular lobe, floating lobe.

May 12th, 1900 , p. 1339 et seq. xas excised by Langenbuch in 1887 and the patient recovered after recurrent hæmorrhage. Bastianelli removed it in 1895 and controlled the hæmorrhage with a cautery. Terrier et Audray, Chirurgie du Foie, Paris, 1901, p. 144. 